\title{
Variações Sobre o Tema: Opinião Pública
}

\author{
RAUL LiMA
}

A A upiniâo pública está situada numa ciência ainda nova, a pșicologia social, oriunda de um movimento de idéias que Gabriel TARDE provocou e dirigiu, atraindo a atenção sôbre as relações entre as duas ordens de fatos: a opinião fública e a multidão. (Fernando de Azevedo, Princípios de Sociologia).

Apesar de ainda na infância, como acentua Getrell (RAymond G. Getrel, História das Idéias Políticas), a psicologia social, estudando cientìficamente os motivos da conduta humana, apurando a importância da opinião pública e apreciando os métodos que influem na sua elaboração, exerceu pcderosa influência na evolução das teorias políticas.

Ross, citado por ARTHUR RAMOs em obra que contém excelente capítulo sôbre a matéria, Introdução à Psicologia Social, definiu-a como uma "discussão que atrai a atenção geral", distinguindo-a da opinião preponderante, assina como TARDE a distinguira da Tradição e da Razão para chegar a êste enunciado: "Opinião é um grupo momentâneo e mais ou menos lógico de julgamento que, respondendo a problemas propostos, em dado momento, se acham reprcduzidos em numerosos exemplares em pessoas do mesmo país, do mesmo tempo e da mesma sociedade"!

O Santo Padre PIo XII considerou-a "o apanágio de tôda sociedade normal", "o éco natural, a ressonância comum, mais ou menos espontânea, dos acontecimentos da situação atual nos seus espíritos e nos seus juízos".

E' a função psicológica do público, dizem os tratadistas; é, para o público, nos tempos modernos, o que a alma é para o corpo.

Acentuam êles a distinção entre a opinião manifestada conjuntamente po: um público ou multidão e a opinião pública pròpriamente dita.

Quanto a primeira, é fruto do ajuntamento, de uma excitação que se generaliza, de um sentimento não raro momentâneo e sem maiores consequiências.

A opinião pública é elaborada mediante um processo no qual se inclui, antes de'mais nada, o acervo moral de cada povo, sua formação, seus costumes e tradições, suas tendências e aspirações. Instrumento para a implantação ou o fortalecimento de uma ideologia ou reivindicação, a educação, tenha sido ou não usada com êsse objetivo, fica sempre fazendo parte daquele patrimônio, próximo ou remcto, daquele background espiritual que assegura ou impede o êxito de movimentos constitutivos da opinião coletiva. 
Ao contrário das manifestações de uma multidão, a opinião pública se produz através da conversação, da comunicação entre indivíduos, dos debates e das reflexões em comum no seio de pequenos grupos, dos bate-bocas; diríamos, sem receic de proferir uma chulice, que resulta de uma grande corrente de mexericos.

Eis porque - e também graças ao caráter de instantaneidade da cornunicação - $\mathrm{c}$ rádio se torna um instrumento mais poderoso do que o jornal, pois, no parecer de um especialista, FREDERICK LAwS, educador e crítico britânico, o microfone, impróprio para a oratória popular, é um perfeito veículo de conversa íntima entre locutor e ouvinte.

NAPOLEÃo (Opiniões Políticas) perguntava: "Que vem a ser o Govêrno, se não tem por si a opinião pública?" E êle próprio respondia: "Nada". Não o entendia assim, porém, para concluir que o govêrno deveria submeter-se a ela. Insurgia-se contra os que a conduziam, contra o tribunato, que, ao seu ver, não devia existir onde não houvesse um patriciado, em países que ainda não estivessem há muito constituídos.

Embora sejam fáceis de encontrar outras frases suas em que reconhece o valor e a importância da opinião pública, não acompanhcu MACHIAVEL nas suas receitas sôbre o moral de uma cidade sitiada. Dizia o florentino que um príncipe poderoso e destemido triunfará sempre das dificuldades ora dando aos súditos a esperança de que o mal não durará muito, ora assustanda-os com as crueldades do inimigo, ora tomando hábeis medidas de segurança contra os mais turbulentos.

A isso opunha NAPOLEÃo: "O meio mais eficaz ou, melhor, único, é contê-los a todos, empregando o terror; tiranizai-os, e êles não se inșurgirão nem ousarão respirar".

Foi também NAPOLEÃo quem feriu o problema ou a necessidade de distinguir entre multidão, o pronunciamento de determinada porção de massa colocada junto ou em face do Govêrno, pressionando-o, e a cpinião pública nacional.

"Enquanto me correr o sangue nas veias, não consentirei que os parisienses me ditem leis" - escreveu êle, acrescentando: "Não aceitei o Império por uma decisão da cidade de Paris, que muda de interêsses e de opinião duas vezes, por dia, mas pelo voto dcs departamentos, do exército e de tôda a França". Problema, êsse, que viria a acutilar o último Imperador do Brasil, vendo alguins milhares de habitantes do Rio de Janeiro, excitados pelo aumento do preço das passagens de bonde a investir contra as grades do Paço de $\mathbf{S}$. Cristóvão, o que arrancou do velho soberano esta reflexão:

"Difícil é a posição de um monarca nesta época de transição. Muito poucas nações estão preparadas para o sistema de govêrno para que se caminha, e eu decerto poderia ser melhor e mais feliz presidente da República do que imperador constitucicnal." 
Dir-se-ia que o período de transição, passados 75 anos, ainda não terminou. E, entre parêntesis, a idéia de mudança da capital para o interior ganha fórça no desejo dos presidentes da república de escaparem às revoluções do vintém ou aumento do preço de cinema, enfim de pressões da opinião pública de grande cidade.

Um filme, de história mais ou menos banal, mostrou-nos, recentemente, interessantes ângulos do problema de opinião pública.

Procurava um técnico em boa apresentação dos indivíduos de grande prcjeção convencer a um dêstes, milionário latino-americano, a contratá-lo para evitar má repercussão de atos ou simplesmente da vida do magnata na pátria đêste. O milionário latino-americano era tão milionário e tão latinoamericano que não se preocupava absolutamente com $\sigma$ problema, pois controlava os instrumentos de opinião pública na republiqueta imaginária, um tanto caricaturada, porém não demasiado longe da realidade.

Outro ângulo do assunto fci mostrado no êrro de tática perpetrado pelo referido técnico. Havendo o pai da estrêla asassinado a espôsa, temeu êle o péssimo efeito do caso sôbre o cartaz da artista, pretendendo abafar o episódio; e mais alarmado ainda ficcu quando soube que a vedete correra a defender o pai, colocando-se assim frontalmente contra um dos mais sólidos cânones sociais, o do amor materno e a devida reciprocidade. Acontece, porém, que a assassinada era uma perfeita megera, que infernava a vida de tcdos, e a atitude da estrêla foi aplaudidíssima, muito the aumentando a fama, à inteira revelia dos cálculos do especialista de Hollywood.

Eis aí flagrantes ilustrativos do que é opinião pública em hipóteses antagônicas: uma a de vedação da informação, a censura, o contrôle da imprensa exercido pelc totalitarismo econômico; a outra a do uso pleno da evidência dos fatos, a política de céu aberto, de amplo esclarecimento.

Relacicnada com o sentido dinâmico do poder político de um Estado na esfera internacional, a formação da Opinião Pública certamente deve ser encarada como o resultado da grande arma dos tempos modernos, a propaganda.

Eis um terreno melindroso.

\section{Tem razão Raynond W. MurRay (Introdução à Sociologia):}

"A propaganda pode ser tão útil quão enganosa. Entretanto, como meio de moldar a opinião pública, ela se tornou cada vez mais desonesta e viciosa ncs últimos anos. Graças à deformação e à repetição, a propaganda quebra a resistência do homem médio até que, finalmente, êle se apressa a adotar a opinião que, segundo foi levado a crer, é sustentada pela maioria. Como quase todos nós desejamos estar com o grupo, sentimo-nos mal quando defendemos um: opinião que é contrária à daquele, assim como ficamos doentes quando 
sofremos a reclusão celular. A propaganda deliberadamente juga com êste instinto gregário, e, sobretudo, pela sugestão procura criar em nós determinados moldes de pensamento ou ação."

Alguns autores, referidos por MURRAY, entendem que estamos sendo ràpidamente abscrvidos por "unidades de multidão", com o pensamento confuso ante a multiplicidade dos meios de difusão de idéias, subordinado às emoções que surgem através do grupo.

Assim, não estaria inteiramente destituíco de razão aquêle pensador político, Graham Wallas, no século passado, ao acentuar o fato de a pclítica só em medida muito restrita ser produto da razão consciente.

Entende que, na sua maior parte, é o resultado dum processo subconsciente, integrado pelo hábito e pelo instinto, pela sugestão e pela imitação. Neste aspecto, destaca a importância dos nomes e dos símbolos, dos lemas dos partidos e dos aspectos emotivos dos programas políticcs; a arte da política estribar-se-á, ùnicamente, na formação da opinião, valendo-se de um chamamento deliberado às sugestões afetivas e às consequiências não-racionais. Em resumo: as grandes decisões pclíticas não representam uma vontade geral, produto da razão e do pensamento definido e ordenado, mas antes dum conjunto de impulsos, interferências, hábitos e preconceitos.

Não há, porém, como recusar-nos a admitir a utilização de um instrumento oue está sendo manejado, desta ou daquela maneira, com maiores ou menòres limitações em face da ética, dentro de princípios democráticos ou do esquema totalitáric, no mundo que acabou se sair de uma experiência esmagadora e definitiva.

Êsse problema e tudo quanto êle implica em relação às técnicas da propaganda política são o conteudo de um livrinho, o de JEAN-MARIE DOMENACH, que se acha demasiado vulgarizado para que seja necessário ocupar-me extensamente das idéias e dos roteiros nêle traçados. Não poderei deixar de fazê-lo de algum modo, mas, antes, desejo, acentuar alguns aspectos particulares e ilustrativos da participação dos órgãos de divulgação num país livre.

$\mathrm{O}$ grande Roosevelt, referindo-se à liberdade de imprensa, enfatizou, rium dos seus discursos:

"Afianço que nenhum homem ou mulher de bom-senso acredita que esta liberdade tenha sido restringido ou ameaçada, ou que venha a ser. A influência da palavra imprensa dependerá sempre de sua veracidade, e a nação pode se:n perigo confiar na sábia discriminação de um público leitor que, com o aumento da educação geral, está habilitado para separar a verdade da ficção. A democracia representativa jamais tolerará que, por uma ordem do govêrno, sejam suprimidas nctícias verdadeiras."

ROOSEVELT, havendo tido contra sua dupla candidatura a maioria da grande imprensa norte-americana, podia bem afirmar as duas coisas: a liberdade de que ela desfrutava e a reação do povo deixando de segui-la. 
Fizera ela bom uso dessa liberdade? Os comunistas chegam a construir um sofisma segundo o qual o jornalista democrático é menos livre do que os soviéticos pois é prisioneiro de uma série de interêsses quer da grande emprêsa, quer da simples condição industrial e lucrativa do jornal, quer dos baixos interêsses dos aventureiros donos de pasquins.

John DEWEy (Liberdade e Cultura) foi um que soube apontar não serem os inimigos da liberdade de imprensa apenas a censura e o contrôle do Govêrno, mencionando a existência de causas não políticas, e o pesado ônus cobrado pelos fatôres econômicos.

O problema fci apreciado, rcentemente, em admirável e corajosa oração de sapiência do Reverendo Álvaro VIEIRA DE MAdUREIRA, licenciado em Teologia pela Universidade de Roma e professor do Seminário Maior do Pôrto, que disse:

"Ninguém ignora, por outro lado, que no mundo da Imprensa, - coma aliás, nnais ou menos, em tôdas as profissões - existe uma escumalha perigosa, mercantilista, sem escrúpulos de qualquer espécie, que apenas causa males à humanidade. Ninguem o nega. Os próprios jornalistas católicos, ccmo notcu Pro XII, ao falar em 12 de maio de 1953 aos membros da Associação dos Jornalistas estrangeiros, de Roma, estão sujeitos a graves e múltiplas tentações, tanto da parte dos partidos políticos, como das emprêsas em que trabalham, como ainda "da opinião pública, ou, mais exatamente, das opinióes do público, que o jornalista não pode seguir sem reservas, êle que precisamente as deve ajustar à verdade e ao direito, e, conseqüentemente, purificar e guiar."

Cuntestação que não tem cabimento é a que incide sôbre a existência de opinião pública neste ou naquele país. Existe sempre, no mínimo certo número de idéias, de sentimentos, de tendências que constituem opinião pública em estado latente, suscetível de atuar, capaz de manifestar-se desde que surjam causas provocadoras ou seja escorvada pela propaganda.

Se é contestável a tese de que cada povo tem a govêrno que merece, pois a verdade é que muitos governos constituem pesadas injustiças sôbre os povos que não têm meios de evitá-los, é defensável a afirmativa de que a qualidađe de um jornal depende mais de quem $c$ lê do que de quem o redige. Quem o justific a é Francis Williams, publicista inglês, em órgão de divulgação da UNESCO - Organização das Nações Unidas para Educação, Ciência e Cultura - esclarecendo o seguinte: "Mesmo no país em que os jornais são teòricamente livres, e onde os princípios democráticos são inscritos na Constituição, a npinião pública nem smpre está disposta a aceitar - e com mais forte razão ^ exigir - noticiários fiéis e imparciais ou comentários objetivos. Nos países politicamente pouco desenvolvidos, onde a instrução é pouco difundida, a opinião pública, mesmo se favorável em princípio à liberdade da imprensa, não se empenha em ter uma imprensa consciente de suas responsabilidades". E acrescenta: "Nessas condições, um jornal arrisca-se a não poder 
sobreviver e manter seus leitores salvo renunciando a assumir as responsabilidades que the incumbem".

Por mais idealista que seja a direção de um jornal, e ainda mesmo que renuncie à disputa dos recursos indispensáveis à sustentação da atividade industrial, em vista de possuí-los em outra origem, não pode deixar de acomodar-se a certas exigências do público, - sob pena de, apesar daquela situação de absoluta independência, não alcançar êsse mesmo público para dcutriná-lo, bem servi-lo, servir a Nação.

Assim, por exemplo, em relação à ccnjuntura econômica. A imprensa orientada patriòticamente deve combater a inflação, pregar a poupança de divisas, e em geral os grandes jcrnais o fazem. Mas o fazem sem coerência, agindo corretamente em relação a alguns aspectos e a outros não.

Combate-se a alta dos preços, os órgãos mais independentes atacam, mesmo duramente, o comércio, os órgãos de contrôle; mas quando se trata de aumentar salários, uma das causas daquela alta, os leitores - na grande maio. ria pertencente à classe de assalariados - querem defesa das suas reivindicações.

Além de tudo, vivendo da propaganda comercial, da expansão das vendas, a imprensa é por natureza instrumento inflacionáric. Por mais que seus colunistas preguem remédio para a crise, os anúncios serão sempre convites para agravá-la.

- O que ficou dito em relação à imprensa, de modo geral, aplica-se igualrriente ao rádio - até onde vai a liberdade, mais restrita, de que êste goza - ao cinema, ao própric teatro popular que é um elemento nada desprezível de formação da opinião.

Nada disto, porém, nos levará à preferência pelo dirigismo, baseado na censura e outros métodos que tornaram famoso o Dr. GoebBels, para quem as massas são um material informe, sòmente nas mãos dos artistas políticos adọuirindo forma de povo e êste se transformando em nação.

Pıo XII, a cuja percuciência e sabedoria não escapa nenhum dos protlemas do mundo contemporâneo, sentenciou: "Abafar (a opinião) dos cidadäos, 1eduzi-la ao silência forçado, é, aos olhos de todos os cristãos um atentado ac direito natural do homem, uma violação da ordem do mundo, como Deus estabeleceu".

Acreditamos na formação da opinião pública para integração do poder politico como resultado da osmose de elites e massas, mediante o emprêgo amplo da :nformaçãc; do esclarecimento e sustentação de uma política firme e de interêsse geral.

$$
* * *
$$

E' verdade que muito tem sido salientado o fato de que "as elites nem sempre são a parte da sociedade que mais nitidamente apreende os interêsses vitais da socidade", ocorrendo assim atrasarem-se em relação às massas. Per- 
dem, dêsse modo, a sua capacidade de influência na formação da opiniãc públic.j, sua tarefa inegável.

Entretanto, êste é um ponto sôbre o qual convém nos determos com algum vagar. Podemos distinguir, entre as elites, a que o é pela sua condição dirigente, a que o é pela formação intelectual e pelas características morais, a que o é pela ação de liderança, a que o é pelo idealismo.

Ora, veremos então elites capazes de interpretar os sentimentos das massas, seguramente muito mais identificadas com elas do que outras, às quais falta o sentido ético de elite mas que se tornaram depositárias da confiança daquelas massas.

Verifica-se, assim, em determinadas circunstâncias, um divórcio incompreensível e injustificável onde não há antagonismo de interêsses nem de tendências. Será o caso em que uma elite, animada pelos melhores sentimentos, proscrita da direção do Estado, não se faça entender pelas massas inclinadas para a demagogia e afeitas à superficialidade e falsidade de soluções imediatistas. Aí não há atraso da elite, verdadeira elite na hipótese figurada, ou tendência para considerar interêsses próprios que se contradigam com interêsses da sociedade a que pertencem; antes há uma profunda, natural porém secreta e impercebida comunhão de tais interêsses.

Como entender, por exemplo, que não se engajem as massas numa luta contra a corrupção, associando-se à elite que a combate em vez de seguir à suposta elite que a pratica? Entretanto tais fenômenos ocorrem e iremos ver que se trata de faltar à primeira a pugnacidade necessária, o uso da propaganda, pois mesmo a verdade, para sobreviver, nãc é suficiente conservá-la no coração de alguns iniciados, como adverte DoMENACH.

"A verdade precisa de um clima para existir e conquistar. Seria vão crer que se pudesse criar-lhe um tal clima, um tal campo de fôrça, num século em que todos os problemas se cclocam em têrmos de massa, sem recorrer ao poderıo de propaganda."

Uma propaganda de ideais, de objetivos, de uma política de segurança nacional, é tarefa que incumbe por igual ao Estado democrático.

Decerto se distinguirá ela pela natureza dos métodos, sendo mister mesmo que se processe antes através de líderes, de participantes e influentes na formação da opinião pública e não meramente por intermédio dos órgãos governamentais.

Tanto quanto a formação da opinião pública, a manutenção de sua esta bilidade é prcblema desafiante, dada a rapidez das comunicações.

Já observou o Padre WILFRed Parsons, S.J., que no mundo moderno as idéias não têm tempo de germinar. E comenta:

'Logo que um sistema de pensamentos começa a mover-se e a viver dentro de nós é imediatamente substituído por outro, insidicsamente semeThante e tremendamente diverso. Outrora, os homens pertenciam a escolas 
de pensamento. Submetiam-se a uma corrente fixa de sugestốes que por fim ocupava todos os espaços de suas consciências. As outras idéias não tinham tempo de alcançá-los e quando isto acontecia, o processo de desalojar as antigas efetuava-se lentamente. Hoje, o mundo pertence a tôdas as escolas de pensamento. Logo que se adota uma idéia - que em geral não é uma idéia e sim a aplicação de uma idéia - outra pula do jornal, do rádic ou do cinema e senta-se ao lado da anterior. O resultado é que nossos espíritos não são um apontada por outrem como "a morte da Verdade pelo Número". Diz êle que: "Na sua vigência, o govêrno identifica-se com partido, o Estado alheia-se ticos", chéga a conclusões desalentadoras sôbre a democracia opinativa, já apontada por outrem como "a morte da Verdade pelo Número". Diz êle que:

"Na sua vigência, o govêrno identifica-se com partido, o Estado alheia-se dos grandes problemas nacionais, os caprichos de uma opinião que flutua como cana ao vento, é que marcam as soluções, é que orientam e desorientan como bem thes apetece. Na Democracia opinativa, os governantes não mandam por direito própria; a máquina estadual limita-se a vigiar as atividades particulares, sem as dirigir ou subordinar ao bem-comum; a assembléia legislativa discute, mas pouco governa."

Eliel C. Ballester, em seu ensaic sôbre a liberdade de imprensa (Derecho de Prensa, Buenos Aires, 1947) aponta exemplos de referência à opinião pública até mesmo na Constituição de um ou outro país. E' o caso da Irlanda, onde se declara "a educação da opinião pública, matéria de grave importância para o bem comum".

Mas é o caso principalmente de Portugal, cuja atual Constituição, no artigo $8 .^{\circ}, \S 2 .^{\circ}$, estabelece que "se regulará mediante leis especiais o exercício da liberdade de expressão do pensamento... devendo-se... impedir e reprimir a perversãc da opinião pública em sua função de fôrça social..." Mais ainda, segundo o autor citado, dispõe o artigo 22: "A opiniaão pública será um eleriento fundamental da política e da administração do país, correspondendo ao Estado defendê-la de todos os fatôres que a desorientam perante a verdađe, a justiça, a boa administração e o bem comum".

Ao ver de Silva Dias, "o mundo anda à procura de uma fórmula de conciliação da Democracia política com a eficiência dos Governcs e com a transformação orgânica da sociedade". Aí estão, talvez, para đemonstrá-lo as limitaçc̃es que a liberdade de imprensa vem sofrendo também em quase todos os países não totalitárics do mundo, como observa o relatório do Instituto Internaciona! da Imprensa, do período 1954-1955.

Segundo êsse relatório, o mais generalizado pretexto para as nações reduzirem a liberdade de imprensa é em nome da segurança, não havendo dúvida de que é essa uma das consequiências da "guerra fria". Novas medidas foram adotadas contra jornais acusados de atacar "os interêsses nacionais" ou "o prestígio nacional", assim como - e aí vai o caminho para todos os abusos - existe uma tendência para proteger as personalidades do Govêrno "contra as críticas da imprensa". 
O relatório não disfarça a gravidade do fato de aparecerem novas formas de pressỗes do Govêrno em países democráticos por tradição e que têm uma longa história de liberdade e vida parlamentar, ccmo a França e a Austrália.

Num sistema de liberdade de manifestação do pensamento, a única arma que sa afigura eficaz é mesmo a da ampla informação, oportuna e exata, a propaganda dos fatos. E não é fácil tarefa o realizá-la, quando os instrumentos de difusão têm a faculdade de reduzir a importância dos accntecimentos saudáveis e positivos e enfatizar os negativos, quando não mesmo de deturpar.

Externamente, a dificuldade se extrema, pois as informações que nuttem a imprensa mundial são manipuladas por agências de sindicatos que fazem largo uso de restrições mentais e de expedientes próprios do ofícic; segundo os quais a opinião internacional é trabalhada em favor ou contra determinado país, segundo convenha aos interêsses dos grupos econômicos ou dos países a que estejam ligados aquêle sindicato.

Para se ter uma idéia dos instrumentc's dessa imensa rêde de comunicações, áqui estão algumas estatísticas elaboradas pela UNESCO, quanto aos países estrangeiros, e pelos órgãos do I.B.G.E. em relação ao Brasil.

\section{IMPRENSA DIÁRIA}

\begin{tabular}{|c|c|c|c|c|}
\hline$P A \mathrm{I} S$ & Dránios & $\begin{array}{l}\text { TVRAGEM } \\
\text { TOTAL. }\end{array}$ & $\begin{array}{l}\text { No. DE EXEMI- } \\
\text { PLARES POR DIA } \\
\text { E POR } 1.000 \\
\text { HABITANTYS }\end{array}$ & $\begin{array}{l}\text { No. DE CIDADES } \\
\text { EM QUE HÁ } \\
\text { DÍ́mOS }\end{array}$ \\
\hline 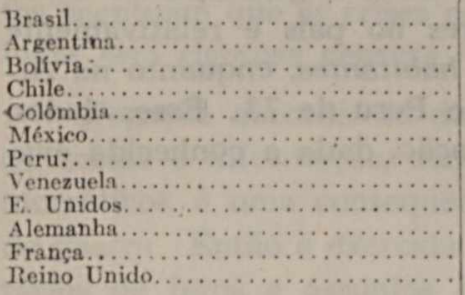 & $\begin{array}{r}254 \\
180 \\
9 \\
39 \\
37 \\
98 \\
41 \\
29 \\
1 \quad 780 \\
162 \\
164 \\
121\end{array}$ & $\begin{array}{rrr}3 & 373 & 500 \\
3 & 460 & 000 \\
& 56 & 000 \\
& 456 & 000 \\
& 600 & 000 \\
1 & 185 & 000 \\
1 & 320 & 000 \\
& 300 & 000 \\
52 & 845 & 550 \\
16 & 500 & 000 \\
10 & 680 & 000 \\
30 & 000 & 000\end{array}$ & $\begin{array}{r}60 \\
209 \\
14 \\
80 \\
55 \\
48 \\
39 \\
65 \\
354 \\
238 \\
259 \\
596\end{array}$ & $\begin{array}{l}73 \\
88 \\
3 \\
23 \\
12 \\
41 \\
23 \\
- \\
- \\
70 \\
66\end{array}$ \\
\hline
\end{tabular}

O número de diários no Brasil, 254, é relativamente elevado, ultrapassando o de todos os países mencionados no quadro acima, exceto os Estados Unidos. Em vista, pcrém, da baixa tiragem da grande maioria dos nossos jornais, o número de exemplares editados por dia é baixo. Resulta dessa baixa tiragem que o número médio de exemplares por dia e por 1000 habitantes é apenas de 60, enquanto na Argentina sobe a 209, nos Estados Unidos a 354, na Alemanha a 238, na França a 259 e no Reino Unido a 596.

Essa baixa prcporção de exemplares por 1000 habitantes (60) é, principalmente, uma conseqüência da extensão do analfabetismo no país. De acôrclo com o censo demográfico de 1950 , entre os 43.573 .517 habitantes em idade de 5 anos e mais sabiam ler e escrever sòmente 18.588 .722 , isto é $42,66 \%$. Estima-se, assim, que o número médio de exemplares por dia e 
por 1000 alfabetizados é de cêrca de 165 a 170 . Essa proporção é muito. baixa, revelando que além do analfabetismo há outras causas que restringem a circulação dos periódicos.

\section{RADIODIFUSÃO}

\begin{tabular}{|c|c|c|}
\hline PA I S & $\begin{array}{l}\text { NÚMERO DE } \\
\text { RECEPTORES }\end{array}$ & $\begin{array}{c}\text { NÚMERO DE } \\
\text { RECEPTORES POR } \\
1.000 \\
\text { HABITANTES }\end{array}$ \\
\hline 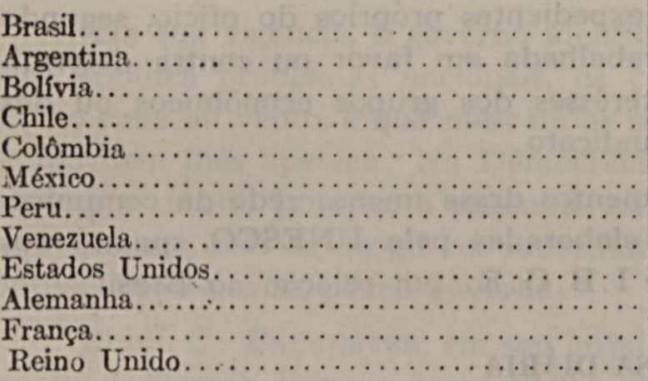 & $\begin{array}{rrr}2 & 500 & 000 \\
1 & 500 & 000 \\
150 & 000 \\
& 550 & 000 \\
& 500 & 000 \\
750 & 000 \\
& 600 & 000 \\
& 200 & 000 \\
92 & 500 & 000 \\
11 & 592 & 000 \\
7 & 400 & 000 \\
12 & 270 & 000\end{array}$ & $\begin{array}{r}51 \\
90 \\
38 \\
96 \\
45 \\
31 \\
73 \\
43 \\
620 \\
167 \\
179 \\
244\end{array}$ \\
\hline
\end{tabular}

O Brasil possui um número de receptores maior do que o de cada um dos países latino-americanos; a Argentina, com 1.500.000 receptores aparece em 2..$^{\circ}$ lugar. Levando-se em consideração, entretanto, a grandeza de nossa população, verifica-se que o número de receptores no país é relativamente baixc, correspondendo 51 aparelhos a cada 1000 habitantes, enquanto na $\mathrm{Ar}$ gentina a proporção é de 90 , no Chile de 96 e no Peru de 73 . Êsses dados, porém, talvez não representem exatamente a situação, dada a conhecida evasão dos registros, nesse particular.

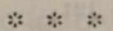

Afora o que ficou exposto, é óbvio que o processo de influência sôbre opinião pública varia de país para país, não havendo como estabelecer regras. cu receitas de aplicação geral.

Há que levar em conta, em primeiro lugar, o regime político vigente, quer no próprio Estado, para fins internos, quer, no âmbito externo, no país sóbre cuja opinião se quer atuar.

Do mesmo modo, aquela utilização tem de ser precedida de um conhecimeitc seguro das características culturais da população sôbre a qual se vai influir. Tais sejam as condições - econômicas, educacionais, sociais - tais serão os meios a empregar.

Não se pode confiar demasiado em impressos para uma coletividade€scassamente alfabetizada, nem na radiofusão onde são raros os receptores. 
Dar-se-ia aquilo que EÇA DE QUEIROZ caricaturou a propósito de movimento de "madrinhas de guerra". Disse êle que tal movimento partia de dcis pressupostos falsos: o de que as senhoras sabiam escrever e o de que os soldados sabiam ler.

Una demonstração ilustrativa sôbre a peculiaridade dos recursos a empregar para a formação ou mobilização da cpinião pública é oferecida, no Brasil, quando se tem de realizar o censo geral da população, para vencer a desconfiança dos campônios, agravada com a semelhança que vêem entre recenseamento e recrutamento. Essa desconfiança tem chegado a produzir verdadeiro pânico em algumas zonas, tendo sido registrado o caso de suicídio de uma pobre mãe ao verificar que haviam falhado seus esforços para que o filho não fôsse recenseado. Essas e outras circunstâncias têm levado as autoridades censitárias a empregar, como um dos instrumentos de penetração. mais seguros, a chamada literatura de cordel, cs livrinhos de versos, a poesia improvisada dos cantadores nas feiras, com ingredientes de misticismo e a colocação das finalidades do grande inquérito decenal em têrmos acessíveis: aos mais rudes.

Os meios de atuar para formar e manter a opinião pública são, como. se sabe, a censura, ou contrôle negativo, e a propaganda, contrôle positivo.

A história registra os antecedentes do exercício da censura pela Igreja e depois pelo Estado, destacando, no passado, a que culminou no movimentoda Revolução Francesa, a que se exerceu no período napoleônico, a que acompi nhou o desenvolvimento do império alemão sob Bismarck. E cs tratadistas acentuam que as crises político-sociais, as crises de transição não são juguladas sem rigorosa censura.

Negação absurda do direito - com tendência a aceitação universal de acesso à informação, constrangimento incompatível com os princípios democráticos, é uma conseqüência imperiosa em situações críticas, em hipótesede guerra. Então é exercida não sòmente em relação às nctícias e aos comentários de fatos e assuntos internos como sôbre as informações procedentes. do exterior ou destinadas ao estrangeiro.

Ao lado dela, nas fases de exacerbação do contrôle da opinião pública, en penha-se o Estado na propaganda - processo psicológico positivo, criador - dirigida igualmente a todos os níveis da organização social e por todos. os meios também empregados pela censura.

A técnica da propaganda constitui hoje uma especialização e, na última guerra, adquiriu tal importância e tanto se enriqueceu, que parecem obsoletos. e ingênucs aquêles princípios ou leis e as regras que estabeleceu KNIGHT' DunLAP, num livro de 1935 Civilized Life, citado por ARTUR RAMOs.

DOMENACH entende mesmo que a propaganda política não é uma ciência condensável em fórmulas. Prefere êle apontar algumas regras de uso, deduzidas, a título de indicação, da história recente. 
São elaș:

- Lei da simplificação e do inimigo único

- Lei de ampliação e desfiguração

- Lei de orquestração

- Lei de transfusão

- Lei da unanimidade e do ccntágio.

A descrição da fisiologia, se assim podemos dizer, ou do mecanismo dessas leis revela-nos traços da ciência e arte do cinismo, mas, ai do Estado que no mundo instável dos nossos dias nãc estiver preparado para empregá-las, ou, sobretudo, se não as conhecer suficientemente bem para defender-se dos que a praticam.

Daí, as fórmulas da contrapropaganda, tão necessária ante a atividade con que, valendo-se das franquias democráticas, quantos, em diferentes partes do mundo, agem a serviço do totalitarismo soviético. São elas, ainda segundo DOMENACH:

$\left.1 .^{\circ}\right)$ Assinalar os termos do adversário.

2..$^{\circ}$ Atacar os pontos fracos.

3..$^{\circ}$ Jamais atacar frontalmente a propaganda adversária quando fôr poderosa,

4. ${ }^{\circ}$ ) Atacar e desconsiderar o adversário.

$\left.5 .^{\circ}\right)$ Colocar a propaganda do adversário em contradição com os fatos .

6. $\left.{ }^{\circ}\right)$ Ridicularizar o adversário.

7..$^{\circ}$ Fazer predominar seu "clima de fôrça".

Para cada uma das leis da propaganda há uma demonstração ilustrativa, que nos colocaria diante de fatos muito do nosso conhecimento. Quando, a propósito da "unanimidade e do contágio", vemos a narração de GALluP dos três alfaiates de Londres que se dirigiram ao rei dizendo "Nós, o povo inglês", iniediatamente nos recordamos dos freqüentes expedientes de quatro "gatos pingados" que, por exemplo, protestam, "em nome do povc", contra uma decisão da O.N.U. inconveniente aos interêsses russos. Constituirá sempre um problema adicional para a segurança de todo país o desfazer os efeitos do persistente trabalho de erosão política e social resultado da sistemática propaganda comunista.

A lição do que se passou na França é sempre lembrada como das mais incisivas. Ainda há poucc, o fez um historiador militar. A. Goutard, nas páginas de Le Figaro Littéraire, citando um alemãc, WALTER GoERLITz: "A propaganda contra a guerra feita pelo partido comunista francês se combinav́: com a campanha empreendida pelas novas unidades alemãs de propaganda para solapar a moral do exército francês. Os aviões alemães jogavam boletins reproduzindo o discurso de Molotov que lançara a responsabilidade da guerra sôbre os capitalistas e os "provocadores de guerra" franceses e inglêses. Uma torrente de jornais, boletins, cartas, volantes, etc., era despejada 
sôbre os soldados franceses da Linha Maginot, pondo em debate a questão de saber se valia a pena "morrer por Dantzig" ou pelos inglêses. Essa forma de guerra provinha de uma idéia cara a Hitler, era sua filha espiritual e pessoal". Acrescenta GoutARD que a essa propaganda impressa se juntava a propaganda por alto-falantes, por cartazes e mesmo por equipes de fraternização que atravessavam o Reno em barcos para entregar a domicílio os discursos de paz do Führer naquele triste período que ficou conhecido como la drôle de guerre.

O contrôle da opinião pública ou o exercício de uma acentuada atuação sôbre ela exige organização, meios poderosos, seguro conhecimento dos fatos que podem alimentá-la e da situação dos setores de opinião diretamente visados.

Sãn êstes abertos as influências diversas, sobretudo a que resulta de decisões governamentais, de tal sorte que, se estas entram em choque com a propaganda, esta pode ser condenada ao fracasso.

Eis porque cumpre reiterar que a melhor propaganda, a realmente compativel com 0 sistema democrático, o meio mais positivo de formar opinião pública, é a difusão de fatos, é a definição de uma política precisa, a explicação e a justificativa dessa política que, por isso mesmo, não pode contradizer-se.

ALFRED SAUVY, grande demógrafo, sustenta a necessidade de manter-se sempre o povo a par dos negócios de Estado, em vez de praticarem cs governos a política segundo o conceitc irônico de VALÉRY, como arte "de impedir que nos envolvamos naquilo que nos diz respeito". 